\title{
Can patients with appendicitis in pregnancy be operated in secondary hospital: A retrospective study
}

\author{
Adnan Budaka , Abdullah Şenlikçi ${ }^{b}$, Ramazan Güven ${ }^{*}$, \\ aBitlis State Hospital, Department of Obstetric and Gynecology, TR-13000, Bitlis, Turkey \\ bBitlis State Hospital, Department of General Surgery, TR-13000, Bitlis, Turkey \\ 'Bitlis State Hospital, Department of Emergency Medicine, TR-13000, Bitlis, Turkey
}

\section{ART I C LE INF O}

\section{Article history:}

Received 10 Febraury 2018

Received in revised form 06 June 2018

Accepted 06 June 2018

\section{Keywords:}

Acute appendicitis

Appendectomy

Fetus

Pregnancy

\begin{abstract}
A B S T R A C T
Appendicitis is the most common non-obstetric cause of acute abdomen in pregnancy. $\overline{\text { Diagnosis of }}$ appendicitis becomes difficult with the change of appendiceal position during pregnancy. Late diagnosis and treatment increase the likelihood of developing perforation. In this study, we aimed to evaluate perioperative outcomes of appendicitis in pregnant patients in secondary hospitals in the light of the literature. 29 pregnant women who performed appendectomy between April 2012 and July 2017 were included in the study. Patients were evaluated according to age, gestational age, white blood cell count, percentage of neutrophil count, C-reactive protein level, ultrasonographic findings, pathologic results, duration of hospitalization and complications. Out of the 29 pregnant patients, $9(31.0 \%)$ patients had surgery during the first trimester, $13(44.8 \%)$ during the second trimester and $7(24.2 \%)$ during the third trimester. Median white blood cell count was $12870 \mathrm{~K} / \mathrm{mm}^{3}$ (min-max;7170-25210). Negative laparotomy rate was \%31.0. Median duration of hospitalization was 3.24 days (2-7). Morbidity was observed in $2(6.9 \%)$ of 29 patients. Intra-abdominal abscess was observed in one patient and colonic fistula was observed in one patient. Our results demonstrated that appendectomy and follow-up of pregnant patients with acute appendicitis can be performed at secondary hospitals.
\end{abstract}

\section{Introduction}

Acute appendicitis is the most common non-obstetric surgical disease in pregnancy and occurs most usual in the second trimester (1). Surgery during pregnancy increase the possibility of spontaneous abortion, preterm delivery, perinatal morbidity and mortality. The rate of maternal death is very low due to improved antibiotics, better perioperative follow-up, and improvements in perioperative patient management (2). Because the position of appendix changes with gestational age, diagnosis of appendicitis during pregnancy is difficult. Delayed diagnosis results in increased risk of developing perforation (3). Although ultrasonography (US) is the most common and easiest method to diagnose appendicitis during pregnancy, recent studies show the superiority of magnetic resonance imaging (4). In this study, we aimed to evaluate perioperative outcomes of appendicitis in pregnant patients in secondary hospital in the light of the literature.

\section{Material and Method}

A total of 29 pregnant women diagnosed with acute appendicitis that underwent an appendectomy in Bitlis and Tatvan State Hospitals between April 2012 and July 2017 were included in this retrospective study. The necessary approvals were obtained from both hospitals and patient data were obtained from medical records. Patients were evaluated according to age, gestational age, white blood cell count, percentage of neutrophil count, C-reactive protein level, ultrasonographic findings, pathologic results, duration of hospitalization and complications. All the patients included in the study were evaluated by gynecologist and general surgeon preoperative and postoperatively, open appendectomy was performed in all cases.

\footnotetext{
* Corresponding author.

Tel.: +0 5323341721

E-mail address: drramazanguven@gamil.com
} 


\section{Results}

Median age of the patients was 25.79 years (min-max;18-36). Out of the 29 pregnant patients, $9(31.0 \%)$ patients had surgery during the first trimester, 13 (44.8\%) during the second trimester and 7 (24.2\%) during the third trimester.

Median white blood cell count was $12870 \mathrm{~K} / \mathrm{mm}^{3}$ (min-max; 7170-25210). Median neutrophil count was $10420 \mathrm{~K} / \mathrm{mm}^{3}$ (min-max; 3440-21870).

Negative laparotomy rate was \%31.0 $(n=9)$. Inflammation of appendix was observed in 20 cases during pathological evaluation. After evaluation with US, 19 patients were diagnosed with acute appendicitis. Diagnosis was confirmed histologically in 17 patients. Acute appendicitis was observed in 3 of 10 patients whose appendices could not be visualized by US. C-reactive protein (CRP) level was evaluated in 22 of 29 patients, median CRP was $30.51 \mathrm{mg} / \mathrm{L}$ (min-max; 0.7129.5). Median duration of hospitalization was 3.24 days (27). Morbidity was observed in 2 (6.9\%) of 29 patients. Intraabdominal abscess was observed in one patient and colonic fistula was observed in one patient. Only 1 (3.4\%) patient had fetal loss (Table 1).

Table 1. Demographic data of all patients.

\begin{tabular}{|c|c|c|c|c|c|c|c|c|c|}
\hline Age & $\begin{array}{l}\text { Leukocyte } \\
\text { Count }\left(\mathrm{mm}^{3}\right)\end{array}$ & $\begin{array}{l}\text { Neutrophil } \\
\text { Count }\left(\mathrm{mm}^{3}\right)\end{array}$ & $\begin{array}{l}\text { CRP } \\
\text { (mg/L) }\end{array}$ & US & Trimester & Pathology & HT & Morbidity & $\begin{array}{l}\text { Fetal } \\
\text { Loss }\end{array}$ \\
\hline 27 & 11480 & 8390 & 42,9 & Neg & 2 & Neg & 2 & No & No \\
\hline 23 & 13070 & 9700 & 102,09 & App & 1 & App & 2 & No & No \\
\hline 29 & 5560 & 3440 & - & App & 1 & App & 4 & No & No \\
\hline 29 & 20280 & 17300 & 129,5 & $\mathrm{Neg}$ & 2 & App & 7 & Colonic fistula & No \\
\hline 34 & 14850 & 12720 & 8,4 & App & 2 & App & 3 & No & No \\
\hline 21 & 13970 & 11450 & 17 & App & 2 & App & 4 & No & No \\
\hline 29 & 15780 & 13540 & - & App & 3 & App & 7 & $\begin{array}{l}\text { Intra- } \\
\text { abdominal } \\
\text { abscess }\end{array}$ & No \\
\hline 22 & 14280 & 9450 & 2,3 & Neg & 1 & Neg & 4 & No & No \\
\hline 27 & 10570 & 8640 & 14,8 & App & 1 & App & 2 & No & No \\
\hline 21 & 17260 & 14130 & 18,1 & App & 1 & App & 2 & No & No \\
\hline 21 & 9910 & 8010 & 3 & Neg & 3 & Neg & 2 & No & No \\
\hline 26 & 10250 & 7590 & - & $\mathrm{Neg}$ & 2 & App & 4 & No & No \\
\hline 28 & 7860 & 5950 & 0,7 & Neg & 3 & Neg & 3 & No & No \\
\hline 36 & 9340 & 6290 & 57,1 & App & 1 & Neg & 2 & No & No \\
\hline 25 & 11570 & 9520 & 16,9 & App & 3 & Neg & 3 & No & No \\
\hline 25 & 14670 & 12270 & - & App & 2 & App & 3 & No & No \\
\hline 23 & 12410 & 10650 & 13,9 & App & 2 & App & 2 & No & No \\
\hline 21 & 11360 & 8950 & 76,6 & App & 3 & App & 5 & No & No \\
\hline 26 & 25210 & 21870 & - & $\mathrm{Neg}$ & 3 & Neg & 4 & No & Yes \\
\hline 18 & 12360 & 9700 & - & $\mathrm{Neg}$ & 2 & Neg & 2 & No & No \\
\hline 32 & 7170 & 5000 & 26,5 & Neg & 1 & Neg & 3 & No & No \\
\hline 27 & 13140 & 11930 & 12,6 & App & 2 & App & 4 & No & No \\
\hline 29 & 8960 & 6390 & - & $\mathrm{Neg}$ & 1 & App & 4 & No & No \\
\hline 23 & 14260 & 11780 & 15,8 & App & 2 & App & 2 & No & No \\
\hline 28 & 13240 & 11650 & 26,9 & App & 2 & App & 3 & No & No \\
\hline 19 & 15370 & 13260 & 35,7 & App & 2 & App & 2 & No & No \\
\hline 27 & 10450 & 8150 & 4,2 & App & 3 & App & 4 & No & No \\
\hline 30 & 15240 & 13240 & 18,46 & App & 1 & App & 3 & No & No \\
\hline 22 & 13560 & 11250 & 27,8 & App & 2 & App & 2 & No & No \\
\hline
\end{tabular}

(App: Acute appendicits Neg:Negative CRP:C-reactive protein US:Ultrasonography HT: Hospitalization time-days)

\section{Discussion}

Acute appendicitis is the most common surgical emergency and affects approximately $7 \%$ of the population (5). $2 \%$ of pregnant women in the world undergo surgical procedures unrelated to pregnancy. The most frequent nonobstetric procedure in pregnant women is appendectomy (4). Acute appendicitis is most commonly seen in the second trimester (1). Similar to what has been reported in the literature, most 
of our patients were in the second trimester. Several studies have reported the prevalence of acute appendicitis in pregnant population to be $1 / 1000$ to $1 / 5533$ (3).

It is difficult to predict the cause of abdominal pain due to special physiological and anatomical changes in pregnancy in pregnant patients. At approximately 12 weeks of gestation, enlarging uterus becomes an abdominal organ and causes pressure on abdominal organs. This enlargement creates difficulty in localizing the pain and affects peritoneal findings (6). During pregnancy, findings of peritoneal inflammation begin to shift upwards and backwards (7). Mild leukocytosis may be a normal finding in pregnant women and this causes difficulty in diagnosis (8). Restriction in radiological methods also causes difficulty in diagnosis (3).

Abdominal pain, fever, leukocytosis, nausea / vomiting and change in bowel habits can be observed in all pregnancies, and these causes difficulty in diagnosis. However, in acute appendicitis nausea and vomiting are seen after the abdominal pain, and pregnant patients have nausea and vomiting not associated with abdominal pain. Ectopic pregnancy should also be considered in differential diagnosis (1). Pyelonephritis should be considered in pregnant patients with pain on the right side. Preeclampsia and HELLP syndrome in the second trimester may cause nausea, vomiting and abdominal pain. (9). In a study of 52 pregnant women with appendectomy, it is reported that appendix perforation is the only cause of maternal morbidity, and if the operation is performed 20 hours after the onset of symptoms, perforation seems inevitable (10). Increased gestational age makes diagnosis difficult and increases the risk of appendix perforation and complication (6). Fetal risks seen in pregnant women with appendicitis are low gestational age, low birth weight, preterm delivery and major congenital anomalies. Major congenital anomalies are seen only in the first trimester. Low gestational age and low birth weight may be associated with increased infant mortality.

Fetal mortality is $1.5 \%$ in uncomplicated appendicitis, in perforated appendicitis the rate increases up to $37 \%$ (11). The fetal mortality rate in our study was $3.4 \%$. Negative appendectomy rate during pregnancy is between $3 \%$ and $23 \%$ in studies performed (4). In our study, negative laparotomy rate was $31 \%$. In their study, McGory et al reported that fetal mortality is higher in patients with negative laparotomy (12).

The use of imaging modalities to diagnose acute appendicitis is limited by the effects of radiation and contrast agents on the fetus. US is the most commonly used imaging technique during pregnancy. But, it is a user-dependent method and normal ultrasonographic findings do not exclude acute appendicitis (13). Because of the risk of radiation and contrast agent, use of computerized tomography is very limited in gestation. It is used only in situations like polytrauma where the life of the mother is at risk. Non-contrast magnetic resonance imaging is useful when US is insufficient in the diagnosis of acute appendicitis. However, there are potential risks to the fetus especially in the first trimester (14).

Laparoscopic surgery in pregnancy causes increased intraabdominal pressure, decreased maternal cardiac output and consequently reduced uteroplacental perfusion. However, some studies suggest that there is no statistical difference between laparoscopic and open appendectomy in pregnancy (14). According to the results of a metaanalysis performed, laparoscopic appendectomy in pregnancy reveals 2 times more baby loss than open appendectomy. There is no difference between groups in terms of preterm delivery, birth weight, APGAR score and wound infection (2).

In conclusion, studies on acute appendicitis in pregnancy in the literature were mostly performed in tertiary hospitals. When our study involving 29 patients was examined, there were no significant differences in the results and complications seen with the literature. Acute appendicitis is the most common surgical emergency that is not associated with gestation in pregnancy and delay in diagnosis may increase the complication rate. According to the results obtained, follow-up and treatment can also be performed at secondary hospitals.

\section{References}

[1] Franca Neto, A.H, Ramos do Amorm, M.M., Virgolina Nobreca, B.M.S., 2015. Acute appendicitis in pregnancy: literature review. Rev Assoc Med Bras, 61(2),170-7.

[2] Wilasrusmee, C., Sukrat, B., McEvoy, M., Attia, J., 2012. Thakkinstian A. Systematic review and meta-analysis of safety of laparoscopic versus open appendicectomy for suspected appendicitis in pregnancy. British Journal of Surgery, 99, 14701479.

[3] Jung, S.J., Lee, D.K., Kim, J.H., Kong, P.S., Kim, K.H., Ba, S.W., 2012. Appendicitis during Pregnancy: The Clinical Experience of a Secondary Hospital. J Korean Soc Coloproctol, 28(3),152-9.

[4] Arer, I.M., Alemdaroğlu, S., Yeşilağaç, H., Yabanoğlu, H., 2016. Acute appendicitis during pregnancy: case series of 20 pregnant women. Ulus Travma Acil Cerrahi Derg; 22(16), 545-8.

[5] Ilhan, E., Senlikci, A., Kızanoglu, H., Ustüner, M.A., Vardar, E., Aykas, A., Yeldan, E., Yıldırım, M., 2013. Do intestinal parasitic infestations in patients with clinically acute appendicitis increase the rate of negative laparotomy? Analysis of 3863 cases from Turkey. Przegląd Gastroenterologiczny; 8 (6), 366-9.

[6] Kapan, S., Bozkurt, M.A., Turhan, A.N., Gönenç, M., Alış, H., 2013. Management of acute appendicitis in pregnancy. Ulus Travma Acil Cerrahi Derg, 19, 20-4.

[7] Kazim, S.F., Inam Pal, K.M., 2009. Appendicitis in pregnancy: 
Experiance of thirty-eight patients diagnosed and managed at a tertiary care hospital in Karachi. International Journal of Surgery, 7, 365-7.

[8] Lurie, S., Rahamim, E., Piper, I., Golan, A., Sadan, O., 2008. Total and differential leukocyte counts percentiles in normal pregnancy. Eur J Obstet Gynecol Reprod Biol., 136(1), 16-9.

[9] Barth, W.H. Jr., Goldberg, J.E. Acute appendicitis in pregnancy. Uptodate. [cited 2014 feb 28]. Available at: http://uptodate.com.

[10] Yilmaz, H.G., Akgun, Y., Bac, B., Celik, Y., 2007. Acute appendicitis in pregnancy- -risk factors associated with principal outcomes: a case control study. Int J Surg, 5, 192-7.

[11] Burcu, B., Ekinci, O., Atak, T., Orhun, K., Eren, T.T., Alimoglu, O.,
2016. Acute appendicitis in pregnancy: Case series and review. North Clin Istanbul, 3(1), 60-3.

[12] McGory, M.I., Zingmond, D.S., Tillou, A., Hiatt, R.J., Ko, C.Y., Cryer, H.M., 2007. Negative appendectomy in pregnant women is associated with a substantial risk of fetal loss. J Am Coll Surg, 205, 534-40.

[13] Wieseler, K.M., Bhargava, P., Kanal, K.M., Vaidya, S., Stewart, B.K., Dighe, M.K., 2010. Imaging in pregnant patients: examination appropriateness. Radiographics, 30, 1215-29.

[14] Walker, H.G.M., Samaraee, A.A., Mills, S.J., Kalbassi, M.R., 2014 Laparoscopic appendicectomy in pregnancy: A systematic review of the published evidence. International Journal of Surgery, 12, 1235-41. 